\title{
ANALISIS PERNIKAHAN USIA DINI DITINJAU DARI SUDUT PANDANG EKONOMI, SOSIAL DAN RELIGI : STUDI PADA KECAMATAN PURWODADI KABUPATEN GROBOGAN
}

\author{
Siti Fatimh Nurhayati, Indah Kurniasari \\ IESP / FEB, Universitas Muhammadiyah Surakarta \\ E-Mail: sfn197@ums.ac.id
}

\begin{abstract}
Abstrak: Penelitian ini bertujuan untuk menganalisis pola pernikahan usia dini dan faktor-faktor yang mendorong terjadinya pernikahan usia dini. Data penelitian menggunakan data primer dengan populasi sebanyak 103 dan diambil sampel sebanyak 50. Metode pengumpulan data melalui observasi, wawancara, angket dan dokumentasi. Alat analisis dalam penelitian ini menggunakan analisis deskriptif kualitatif. Hasil penelitian menunjukkan terdapat 2 alasan dalam melakukan pernikahan usia dini yaitu karena keinginan sendiri dan dijodohkan. Terdapat 3 pola pernikahan usia dini yaitu dispensasi dari pengadilan agama, menuakan umur di KTP dan nikah siri, serta ada beberapa faktor pendorong terjadinya pernikahan usia dini yaitu meliputi faktor ekonomi, faktor sosial dan faktor religi.
\end{abstract}

Kata Kunci: Pernikahan usia dini, faktor ekonomi, sosial dan religi.

Abstract: This study is entitled "Analysis of Early Age Marriage From an Economic, Social and Religious Perspective: Study in Purwodadi District Grobogan Regency" with the aim of analyzing patterns of early marriage and factors that encourage early marriage. The research data uses primary data with a population of 103 and taken as many as 50 samples. Methods of data collection through observation, interviews, questionnaires and documentation. The analytical tool in this study uses descriptive qualitative analysis. The results showed that there were 2 reasons for early marriage, namely because of their own desires and arranged marriages. There are 3 patterns of early marriage, namely dispensation from the religious court, increasing the age of the KTP and siri marriage, and there are several factors driving the occurrence of early marriage which include economic factors, social factors and religious factors.

Keyword: Early age marriage, economic, social and religious perspective.

\section{PENDAHULUAN}

Saat ini bisa dikatakan sudah berada di zaman modern dimana ilmu pengetahuan dan teknologi semakin berkembang pesat. Meskipun demikian tidak otomatis mengubah pola pikir sebagian masyarakat yang masih berpegang teguh pada nilai dan norma yang berlaku dalam masyarakat. Ada dua tipe masyarakat, yaitu (Ritzer dan Goodman; 2014: 90): Pertama, masyarakat organik yang sifatnya individualis yaitu masyarakat yang tidak memiliki jiwa solidaritas, serta menganggap bahwa mereka bisa melakukan semua hal sendiri tanpa memerlukan bantuan orang lain. Kedua, masyarakat mekanik yaitu masyarakat yang suka berbaur dan memiliki jiwa solidaritas yang tinggi, serta adat istiadat dan nilai sosial yang masih sangat terikat.

Keluarga merupakan bagian terkecil dari masyarakat dan negara yang keduanya saling mempengaruhi. 
Keluarga merupakan suatu sistem di mana terdapat hubungan yang spesifik, aturan-aturan, dan peran-peran dari masing-masing anggota yang memiliki keunikan tersendiri (Sugarda; 2001).

Keluarga dibentuk atas dasar pernikahan. Dalam agama Islam pernikahan merupakan sunnah nabi Muhammad SAW. Pernikahan sangat dianjurkan agar dorongan terhadap keinginan biologis dan psikisnya dapat tersalurkan secara halal yang bertujuan untuk menghindarkan diri dari perbuatan zina (Ramulyo; 2004: 1). Adapun tata cara pernikahan diatur secara rinci dalamPeraturan Pemerintah Republik Indonesia (PPRI) Nomor 9 Tahun 1975 Bab 3 Pasal 10 dan 11. Masyarakat di kecamatan Purwodadi sendiri dikategorikan dalam tipe masyarakat mekanik. Hal ini disebabkan karena jika ada permasalahan dalam suatu keluarga kecil otomatis keluarga besar akan terlibat. Di Purwodadi masih banyak terjadi kasus pernikahan usia dini, berdasarkan catatan kantor urusan agama (KUA) kecamatan Purwodadi tercatat data terbanyak pada tahun 2016 terdapat 82 pasangan yang melakukan pernikahan usia dini.

Adapun tujuan penelitian ini adalah menganalisis penyebab terjadinya pernikahan usia dini dan polanya, serta faktor-faktor pendorong terjadinya pernikahan usia dini di kecamatan Purwodadi kabupaten Grobogan ditinjau dari sudut pandang ekonomi, sosial, dan religi. Islam memang tidak melarang umatnya melakukan pernikahan usia dini, akan tetapi bukan berarti bahwa Islam membuka jalan selebar-lebarnya untuk melakukan pernikahan dan membolehkan umatnya melakukam pernikahan semaunya kapan dan dimana saja (Shihab; 2005: 109).

Menurut Undang-Undang Nomor 1 Tahun 1974 (ayat 1) menyatakan bahwa pernikahan dilakukan jika pihak laki- laki sudah mencapai usia 19 tahun dan perempuan usia 16 tahun dengan ketentuan harus ada ijin dari orang tua. Namun jika terjadi hal yang menyimpang dari undang-undang tersebut, seperti adanya pergaulan bebas yang berakibat seorang perempuan hamil di luar pernikahan dan perempuan tersebut belum mencapai usia 16 tahun dan lakilaki belum mencapai usia 19 tahun. Maka Undang-Undang Nomor 1 Tahun 1974 masih dapat memberikan kemungkinan dari batas usia yang telah ditetapkan, yaitu dengan meminta dispensasi kepada pihak yang berwenang. Hal ini didasarkan pada pasal 7 ayat 2 Undang-Undang Nomor 1 Tahun 1974 yang menyatakan dalam hal penyimpangan terhadap ayat 1 pasal ini dapat meminta dispensasi kepada pengadilan atau pejabat lain yang ditunjuk oleh kedua orang tua pihak lakilaki maupun pihak perempuan.

Islam memberikan batasan-batasan dalam melakukan pernikahan agar tujuan pernikahan dapat tercapai yaitu membentuk rumah tangga (bahagia sakinah, mawaddah warahmah), regenerasi (reproduksi), memenuhi tuntutan hajat tabiat kemanusiaan, menjaga kehormatan serta sebagai bentuk ibadah ('Utsman; 2017: 75). Hal ini sejalan dengan Firman Allah SWT dalam Quran Surat ar-Ruum (30) ayat 21:

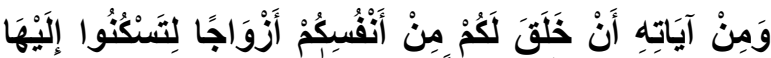

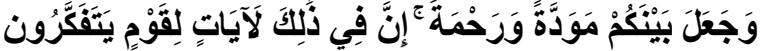

Artinya:

Dan di antara tanda-tanda kekuasaan-Nya ialah Dia menciptakan untukmu isteriisteri dari jenismu sendiri, supaya kamu cenderung dan merasa tenteram kepadanya, dan dijadikan-Nya diantaramu rasa kasih dan sayang. Sesungguhnya pada yang demikian itu benar-benar terdapat tanda-tanda bagi kaum yang berfikir.(Muthoifin \& Nuha, 2015) 
Penentuan batas minimum usia pernikahan langsung mempengaruhi kualitas dalam kehidupan berumah tangga. Kehidupan rumah tangga merupakan benteng pertama dan utama dalam menanggulangi permasalahan kehidupan di masyarakat, karena berawal dari keluargalah permasalahan yang ada di masyarakat dapat terselesaikan dengan baik dan efektif.

Pernikahan dini adalah suatu pernikahan yang terjadi terlalu cepat diusia muda, yaitu dilakukan oleh pasangan yang berusia 18 tahun kebawah baik itu laki-laki maupun perempuan. Hal ini dikarenakan tingkat ekonomi yang rendah, pendidikan rendah serta faktor akses informasi yang tidak memadai. (Khalilah; 2000: 79).

Menurut Fauji; 2018: 385-397 menyebutkan faktor-faktor penyebab pernikahan usia dini, yaitu faktor ekonomi, pendidikan, orang tua, media massa dan internet, biologis, hamil diluar nikah.

Menurut Fauji (2018: 385-397) menyebutkan dampak positif dan negatif pernikahan usia dini, yaitu:

1. Dampak positif : pola berfikir dan lbh mandiri

2. Dampak negatif : menghambat terjadinya proses pendidikan dan pembelajaran dan berresiko thd kesehatan

Penelitian terdahulu yang terkait dengan penikahan dini diantaranya:

1. Penelitian Hastuti (2016) menunjukkan bahwa responden terpaksa menikah dini karena positif hamil di luar nikah.

2. Penelitian Novita(2016)menunjukkan bahwa faktor penyebabnya adalah pendidikan rendah pihak yang bersangkutan dan orang tuanya

3. Penelitian Fauji (2018) menjelaskan faktor-faktor penyebab pernikahan usia dini yang terjadi di desa Barurejo yaitu pendidikan dan ekonomi serta pergaulan bebas

4. Penelitian Zuraidah menunjukkan faktor yang berhubungan dengan usia penikahan adalah pengetahuan, sikap, budaya, ekonomi dan pergaulan remaja.

5. Penelitian Djamilah menunjukkan bahwa ada beberapa faktor yang berpengaruh terhadap perkawinan dini di antaranya adalah faktor pendidikan, kurangnya pemahaman kesehatan reproduksi pada remaja sehingga menyebabkan perilaku seks berisiko di kalangan anak-anak, faktor ekonomi (kemiskinan), faktor budaya (tradisi/ adat), dan perjodohan.

6. Penelitian Arimurti

menunjukkan bahwa faktor yang bekontribusi yaitu rendahnya pengetahuani, rendahnya pemanfaatan media masa sebagai sarana mencari informasi, pengalaman orang tua, keluarga maupun lingkungan.

7. Penelitian Widyawati menunjukkan bahwa penyebabnya adalah tingkat pendidikan yang rendah, pendapatan dan religiusitas.

8. Penelitian Montazeri (2016) di Ahvaz Iranmengungkapkanbahwabeberapa faktor penentu seperti struktur keluarga, otonomi yang rendah dalam pengambilan keputusan, dan respon terhadap kebutuhan sosial, emosional, dan seksual didorong mereka menikah dini. Temuan ini memiliki implikasi untuk pembuat kebijakan, perencana, dan praktisi kesehatan untuk dikembangkan program dan intervensi yang sensitif secara budaya disesuaikan dengan kebutuhan gadis remaja. Programprogram ini harus ditekankan pemberdayaan anak perempuan untuk membuat keputusan yang tepat dan mempersiapkan mereka 
untuk menikah dengan cara yang tepat dan waktu. Mengingat bahwa pernikahan dini adalah masalah multifaktorial, Seharusnya pendekatan multidimensi dan lintas sektoral dianggap mengembangkan dan mengimplementasikan yang efektif dan komprehensif program yang bertujuan meningkatkan kesadaran di kalangan keluarga dan masyarakat mengenai konsekuensi negatif dari pernikahan dini.

9. Penelitian Choe (2005) di Nepal menunjukkan bahwa pernikahan dini dan menjadi ibu muda cukup umum di kalangan perempuan dan pria Nepal, terutama di daerah pedesaan. Penyebabnya adalah pendidikan, wilayah tempat tinggal dan etnis.

10. Penelitian Birech (2013) menunjukkan wanita berpendidikan memiliki lebih banyak peluang untuk meningkat kesejahteraan mereka sendiri dan keluarga mereka secara berkelanjutan daripada wanita tanpa pendidikan. Alasan lainnya adalah budaya. Menurut penelitian yang dilakukan di Ethiopia oleh ICRW, anak-anak ditunangkan sebelum lahir memperkuat aliansi strategis antar keluarga.

11. Penelitian Mahato (2016) di distrik Dha-nusha Terai menunjukkan bahwa insiden perkawinan anak benar-benar salah satu masalah serius dan penting mengenai perlindungan anak karena masih terjadi di seluruh dunia pada abad ke-21. Sebagian besar terlihat di Asia Selatan, Afrika dan Amerika Latin. Juga mengkhawatirkan kita bahwa insiden pernikahan anak lebih tinggi di Nepal dibandingkan dengan negara-negara Asia Selatan. Meskipun sebagian besar berakar pada masyarakat miskin, terpinggirkan dan buta huruf adalah dimensi lain untuk dipikirkan dalam konteks Nepal. Konsekuensi dari pernikahan anak juga mengerikan bagi anak perempuan dalam hal kesehatan dan hak pendidikan mereka karena sebagian besar anak perempuan tersebut putus sekolah setelah menikah. Mereka menghadapi isolasi dan depresi, serta berisiko tinggi terkena penyakit menular seksual, infeksi, dan kanker serviks. Sebagian besar dari mereka meninggal.

12. Penelitian Besral (2018) di perguruan tiggi di Indonesia menjelaskan penentu pernikahan dini di Indonesia adalah kehamilan yang tidak diinginkan, pengaruh teman sebaya, orang tua peran, tingkat pendidikan, pengetahuan kesehatan reproduksi, status ekonomi keluarga, budaya, dan media paparan. Meninjau hukum pernikahan Indonesia diperlukan untuk mengurangi kasus pernikahan dini di Indonesia Indonesia. Meningkatkan kualitas layanan kesehatan reproduksi, meningkatkan pendidikan wanita dan meningkatkan status ekonomi keluarga sama pentingnya untuk mencegah pernikahan dini dan meningkatkan kesehatan ibu dan anak di Indonesia.

\section{METODE PENELITIN}

Populasi dari penelitian ini adalah pelaku pernikahan usia dini yang berjumlah 103 orang yang diperoleh dari data tahun 2016-2019. Adapun penentuan jumlah sampel dengan menggunakan rumus Slovin ( dalam Sevilla et.al, 2007; 182) dengan rumus sebagai berikut:

$$
\mathrm{n}=\frac{N}{1+N e^{2}}
$$

Keterangan

$\mathrm{n}$ : JumlahSampel Minimal

$\mathrm{N}$ : Populasi

e : Error Margin 
Berdasarkan adjustment peneliti perubahannya. Dengan demikian diambil error $=10 \%$ atau 0, 1 dengan diperoleh jumlah sampel sebanyak 50 alasan bahwa variabel ekonomi mudah dengan metode convenience sampling berubah dan sulit untuk mengetahui (tabel-1).

Tabel-1.Tabel Penentuan Sampel

\begin{tabular}{|c|c|c|c|}
\hline Tahun & $\begin{array}{c}\text { Jumlah } \\
\text { Pernikahan } \\
\text { Usia Dini }\end{array}$ & Prosentase $(\%)$ & Sampel \\
\hline 2016 & 82 & $79,6 \%$ & 40 \\
\hline 2017 & 6 & $5,8 \%$ & 3 \\
\hline 2018 & 7 & $6,8 \%$ & 3 \\
\hline 2019 & 8 & $7,8 \%$ & 4 \\
\hline Total & 103 & $100 \%$ & 50 \\
\hline
\end{tabular}

Sumber: Hasil Penelitian Melalui Observasi di Kecamatan Purwodadi Kabupaten Grobogan Tahun 2019.

Secara lebih rinci definisi operasional variabel dalam penelitian ini dapat dilihat pada tabel-2.

Tabel-2.Definisi Operasional Variabel Penelitian dan Pengukurannya

\begin{tabular}{|c|c|c|}
\hline Variabel & Definisi & Indikator dan Pengukurannya \\
\hline $\begin{array}{l}\text { Pernikah-an } \\
\text { Usia Dini }\end{array}$ & $\begin{array}{l}\text { Pernikahan usia dini adalah } \\
\text { suatu pernikahan yang terjadi } \\
\text { terlalu cepat diusia muda, yaitu } \\
\text { dilakukan oleh pasangan yang } \\
\text { berusia } 19 \text { tahun kebawah baik } \\
\text { itu laki-laki maupun perempuan } \\
\text { (Menurut Khalilah; 2000: 79). }\end{array}$ & $\begin{array}{l}\text { 1. Laki-laki dibawah usia } 19 \text { tahun } \\
\text { 2. Perempuan dibawah usia } 16 \text { tahun } \\
\text { (Menurut Khalilah; 2000: } 79 \text { ). }\end{array}$ \\
\hline $\begin{array}{l}\text { Sudut } \\
\text { Pandang } \\
\text { Ekonomi }\end{array}$ & $\begin{array}{l}\text { Struktur kegiatan perekonomian } \\
\text { yang menyebabkan perubahan } \\
\text { dalam kehidupan masyarakat } \\
\text { (Menurut Todaro; 2000). }\end{array}$ & $\begin{array}{l}\text { 1. Pendapatan } \\
\text { 2. Pekerjaan } \\
\text { 3. Tabungan } \\
\text { 4. Investasi } \\
\text { 5. Indeks Biaya Hidup } \\
\text { (Menurut Todaro; 2000). }\end{array}$ \\
\hline $\begin{array}{l}\text { Sudut } \\
\text { Pandang } \\
\text { Sosial }\end{array}$ & $\begin{array}{l}\text { Nilai-nilai sosial dan struktur } \\
\text { sosial yang menyebabkan } \\
\text { perubahan dalam kehidupan } \\
\text { masyarakat (Menurut Todaro; } \\
\text { 2000). }\end{array}$ & $\begin{array}{l}\text { 1. Tingkat Melek Huruf } \\
\text { 2. Tingkat Pendidikan } \\
\text { 3. Lingkungan Tempat Tinggal } \\
\text { 4. Kondisi dan kualitas pelayanan } \\
\text { kesehatan. } \\
\text { 5. Kecukupan kebutuhan akan } \\
\text { perumahan. } \\
\text { 6. Fasilitas sosial dasar seperti (listrik, air } \\
\text { bersih, gas dan sebagainnya). } \\
\text { (Menurut Todaro; 2000). }\end{array}$ \\
\hline
\end{tabular}




\begin{tabular}{|c|c|c|}
\hline Variabel & Definisi & Indikator dan Pengukurannya \\
\hline $\begin{array}{l}\text { Sudut } \\
\text { Pandang } \\
\text { Religi }\end{array}$ & $\begin{array}{l}\text { Agama berasal dari bahasa } \\
\text { Sansekerta, yaitu ' } a \text { ' yang } \\
\text { berarti tidak dan 'gama' berarti } \\
\text { kacau. Agama berarti tidak } \\
\text { kacau. Dengan demikian, agama } \\
\text { adalah peraturan yang mengatur } \\
\text { keadaan manusia mengenai } \\
\text { sesuatu yang gaib, mengatur } \\
\text { budi pekerti dan mengatur } \\
\text { pergaulan dalam hidup (Menurut } \\
\text { Raiya; 2008). }\end{array}$ & $\begin{array}{l}\text { 1. Keimanan (iman kepada Allah, } \\
\text { iman kepada malaikat, dan sebagainya). } \\
\text { 2. Praktik Keseharian (Sholat, zakat, } \\
\text { naik haji, puasa, dan sebagainya). } \\
\text { 3. Hal-hal yang diperintahkan Islam } \\
\text { (rendah hati, menghormati orang tua, } \\
\text { saling membantu). } \\
\text { 4. Hal-hal yang diharamkan. } \\
\text { 5. Nilai-nilai universal dalam Islam } \\
\text { (Memandang setiap muslim sebagai } \\
\text { saudara). } \\
\text { (Menurut Raiya; } 2008 \text { ). }\end{array}$ \\
\hline
\end{tabular}

Data yang digunakan dalam penelitian ini terdiri dari data primer dan data sekunder yang dikumpulkan dengan cara observasi, wawancara dan menggunakan kuesioner. Metode analisis data menggunakan analisis deskriptif. (Muthoifin, 2015) Analisis pernikahan usia dini ditinjau dari sudut pandang ekonomi, sosial dan religi diproksi dengan menganalisis pendapat pelaku pernikahan usia dini dihubungkan dengan alasan melakukan pernikahan usia dini yang dikaitkan dengan melihat latar belakang ekonomi, sosial dan religi. (Muthoifin \& Nuha, 2016)

\section{HASIL DAN PEMBAHASAN}

Analisis alasan dan pola pernikahan usia dini

Berdasarkan alasan mereka melakukan pernikahan usia dini terbesar yaitu 44\% (22 orang) mereka dengan kesadaran diri melakukan pernikahan usia dini dengan tujuan menghindari hal-hal yang tidak diinginkan, 42\% (21 pasangan) disebabkan oleh kehendak orang tua untuk menjodohkan anaknya dengan tujuan mengurangi beban ekonomi keluarga dan sebanyak 14\% (7 pasangan) dimana pernikahan usia dini terpaksa dilakukan karena disebabkan sudah hamil di luar nikah. Jika dianalisis lebih lanjut dari data tersebut nampak bahwa pernikahan usia dini sudah membudaya di lokasi penelitian (kecamatan Purwodadi). Artinya di daerah tersebut merupakan sesuatu yang wajar untuk melakukan pernikahan di bawah umur.

Guna menganalisis bagaimana pola pernikahan usia dini nampak bahwa kasus terbanyak $44 \%$ (22 pasangan) adalah dilakukan dengan cara menuakan umur di KTP dan sebanyak 40\% (20 pasangan) dengan cara meminta dispensasi dari pengadilan agama dan kasus terendah dengan jumlah 16\% (8 orang) dengan cara menikah siri.

\section{Faktor-faktor yang mendorong terjadinya pernikahan usia dini:}

1. Faktor ekonomi

Berdasarkan hasil analisis data responden terkait dengan faktor ekonomi maka nampak bahwa secara umum mereka melakukan pernikahan usia dini dengan alasan untuk mengurangi beban ekonomi keluarga terdapat kasus sebanyak $42 \%$ (21 pasangan) dan dilihat dari latar belakang keluarga dengan mata pencaharian orang tua sebagai petani dengan jumlah $66 \%$ (33 pasangan) dengan kategori jumlah saudara 
terbesar pada suami yang memiliki saudara 4 dengan proporsi $32 \%$ (16 orang) dan istri memiliki saudara 3 dengan proporsi 34\% (17 orang). Sementara yang bersangkutan berlatar belakang pendidikan relatif rendah terbanyak lulus SMP 70\% (35 pasangan) meski ada yang sedikit lulus SMA 4\% (2 pasangan), dengan profesi terbanyak sebagai buruh bangunan 56\% (28 pasangan) dan tinggal dirumah hasil warisan dari orang tua $76 \%$ (38 pasangan) dengan pendapatan yang relatif pas-pasan (bisa memenuhi kebutuhan pokok).

\section{Faktor sosial}

Berdasarkan hasil analisis data responden terkait dengan faktor sosial maka nampak bahwa secara umum rata-rata mereka termasuk orangorang yang melakukan sosialita dengan lingkungan masyarakat sekitarnya, sehingga mereka cukup mengerti apa arti penting dan tujuan berumah tangga. Pandangan mereka mengenai fungsi anak adalah sebagai investasi hari tua sebanyak 20\% (10 pasangan), memandang anak sebagai penerus keturunan $74 \%$ (37 pasangan) memandang anak sebagai ibadah $6 \%$ (3 pasangan). Pemahaman mereka tentang undang-undang pernikahan sangat kurang, terbukti ada 68\% (34 pasangan) tidak paham dengan batas usia menikah. Sedangkan yang paham undang-undang pernikahan dan paham batas usia menikah hanya 32\% (16 pasangan). Jika dilihat dari tradisi atau budaya dilokasi tersebut masih banyak terjadi pernikahan di bawah umur $58 \%$ (29 pasangan) atas keinginan sendiri untuk menikah dan $42 \%$ (21 pasangan) karena dijodohkan.(Muthoifin, 2016)

3. Faktor religi

Berdasarkan hasil analisis data responden terkait dengan faktor religi maka nampak bahwa secara umum mereka mempunyai tingkat religiusitas yang lumayan dalam arti sebagian besar menjalankan sholat lima waktu dan menjauhi larangan agama $80 \%$ (40 pasangan), meskipun ada sebagian kecil yang belum menjalankan perintah agama secara baik 20\% (10 pasangan). Dengan demikian mereka memahami hukum pernikahan dan kenapa harus menikah. Mereka juga memahami bahwa menikah merupakan sebuah kewajiban dan penyempurna ibadah. Mereka berpendapat bahwa agama mempunyai arti penting dalam kehidupan sehari-hari, sehingga mereka juga mengajarkan ilmu agama kepada anak-anaknya meskipun terkadang melalui lembaga keagamaan seperti TPA, dan diajak ke masjid 100\% (50 pasangan). (Muthoifin, 2019)

\section{PENUTUP}

Berdasarkan hasil penelitian maka dapat ditarik simpulan sebagai berikut: Alasan, budaya atau tradisi dan pola pernikahan usia dini. Pernikahan usia dini banyak terjadi dengan alasan karena keinginan sendiri (menghindari zina), dijodohkan dan menghindari hal yang tidak diinginkan (hamil diluar nikah). Selain itu budaya atau tradisi mendukung terjadinya pernikahan usia dini. Berdasarkan hasil analisis diketahui ada 3 pola pernikahan usia dini yaitu kasus terbesar dengan pola menuakan umur di KTP, ke dua dengan cara meminta dispensasi dari pengadilan agama dan yang terakhir dengan pola nikah siri.

Faktor-faktor pendorong terjadinya pernikahan usia dini: Faktor ekonomi. Perekonomian keluarga memiliki peran sangat penting dalam terjadinya pernikahan usia dini. Terbanyak mata pencaharian orang tua sebagai petani dan 
berpendidikan SD serta memiliki anak tentang undang-undang pernikahan rata-rata 3 sampai dengan 4 . Sementara sangat kurang, sehingga sebagian kondisiekonomidari pasangan responden besar dari mereka tidak paham dengan yang melakukan pernikahan dini rata- batas usia ideal untuk melakukan rata mereka berlatar belakang pendidikan pernikahan. Faktor religi. Tingkat relatif rendah yaitu SMP, bekerja sebagai religiusitas juga berpengaruh dalam buruh bangunan dengan pendapatan terjadinya pernikahan usia dini. Berdasar yang pas-pasan dan memiliki tempat hasil analisis data penelitian mereka tinggal hasil dari warisan orang tua. mempunyai tingkat religiusitas yang Faktor sosial. Kondisi sosial lingkungan lumayan dalam arti sebagian besar sudah masyarakat sangat berpengaruh dalam menjalankan perintah agama dengan terjadinya pernikahan usia dini. Ada baik, meskipun ada sebagian kecil yang tiga cara dalam memandang fungsi anak belum menjalankan perintah agama yaitu terbesar sebagai penerus keturunan, dengan baik. Mereka juga berpendapat sebagai investasi hari tua dan sebagai bahwa agama mempunyai arti penting ibadah. Sedangkan pemahaman mereka dalam kehidupan sehari-hari.

\section{DAFTAR PUSTAKA}

Abror, Khoirul. Hukum Perkawinan dan Percraian. Lampung: Pusat Penerbitan dan Penelitian LP2M. 2015. 1-59.

Adhim, Muhammad Fauzil. Indahnya Pernikahan Dini. Yogyakarta: Gema Insani Press. 2010

Aprianti. "Fenomena Pernikahan Dini Membuat Orang Tua dan Remaja Tidak Takut Mengalami Kehamilan Tidak Diinginkan". Jurnal Promosi Kesehatan Indonesia. 2018; Vol. 13 (1): 222-230.

Arimurti, Intan dkk. "Analisis Pengetahuan Perempuan Terhadap Perilaku Melakukan Pernikahan Usia Dini Di Kecamatan Wonosari Kabupaten Bondowoso". The Indonesian Journal of Public Health.2017; Vol. 12(2):249-262.

Basyir, Ahmad Azhar. Hukum Perkawinan Islam. Yogyakarta: UII Press ;2004. 2.

Besral. "Determinants Of Early Marriage In Indonesia: A Systematic Review". International Journal of Science and Health. 2018. No. 3.

Birech. "Child Marriage: A Cultural Health Phenomenon". International Journal of Humanities and Social Science. 2013;Vol. 3(17).

BKKBN. 2010. Pendewasaan Usia Perkawinan dan Hak-hak Reproduksi Bagi Remaja Indonesia. Jakarta: Direktorat Remaja dan Perlindungan Hak-hak Reproduksi.

Choe. "Early Marriage And Early Motherhood In Nepal". Journal of Biosocial Science. Cambridge University Press. 2005; Vol.37;143-162

Departemen Agama RI. Al-Qur'an dan Terjemahnya. Bandung: Jumanatul'Ali-Art (JART) .2005. 407.

Djamilah \& Reni Kartikawati. "Dampak Perkawinan Anak di Indonesia”. Jurnal Studi Pemuda. 2014; Vol. 3(1).

Fauji, Abdi Hadiono. "Pernikahan Dini Dalam Perspektif Psikologi Komunikasi". Jurnal Pendidikan, Komunikasi dan Pemikiran Hukum Islam. 2018;Vol. IX, (2): 385397. 
Hastuti, Puji dkk. "Gambaran Terjadinya Pernikahan Dini Akibat Pergaulan Bebas". Jurnal Riset Kesehatan. 2016;Vol. 5 (1);11 - 13.

Imron, Ali. Pendidikan Kesehatan Reproduksi Remaja. Yogyakarta: Ar-Ruzz Media. 2012.

KBBI (Online). Tersedia di: http://bahasa.kemdiknas.go.id/kbbi/index.php. Diakses pada 22 September 2017.

Khalilah, Marhiyant. Romantika Perkawinan. Jawa Timur: Putra Pelajar. 2000.79.

Mahato. "Causes and Consequences of Child Marriage: A Perspective". International Journal of Scientific \& Engineering Research. 2016. Vol. 7, Issue 7, (698): 2229-5518.

Montazeri. “Determinants of Early Marriage from Married Girls' Perspectives in Iranian Setting: A Qualitative Study". Journal of Environmental and Public Health. 2016. ID 8615929;8.

Muthoifin. (2015). Seminar Nasional Novel 12 Menit Perspektif Pendidikan Islam : Isbn: 978-602-361-004-4 Seminar Nasional ISBN : 978-602-361-004-4. 203-210.

Muthoifin. (2016). Rekonstruksi Epistemologi Pendidikan Islam Dalam Pandangan Ibn Jamaah Dan Ki Hadjar Dewantara Muthoifin 201-210.

Muthoifin. (2019). Shariah hotel and mission religion in surakarta indonesia. Humanities and Social Sciences Reviews, 7(4), 973-979.

Muthoifin, \& Nuha. (2015). Model Penyelesaian Konflik Antar Kelompok dengan Pendekatan Mahfudzat. Prosiding 96-108.

Muthoifin, \& Nuha. (2016). the Optimization of Local Autonomy Politic for Nation Progress and Synergetic on Islamic Perspective. The 4th University Research Coloquium 2016, 72-79.

Novita, Herni, dkk. "Faktor Dominan Penyebab Pernikahan Usia Dini Di Kecamatan Banjarmasin Selatan Tahun 2010-2014". Jurnal Pendidikan Geografi. 2016;Vol. 3(5) 2016;15-21

Raiya, Abu. A psychological measure of Islamic religiousness: Evidence for relevance, reliability and validity. Ohio: Bowling Green State University; 2008.

Ritzer, George \& Goodman Douglas J. 2014. Sociological Theory. Cet. X. Bandung: Kasihan Kreasi Wacana

Sekaran, Uma. Metodologi Penelitian Untuk Bisnis. Jakarta: Penerbit Salemba Empat. 2006.

Shihab, M Quraish. Perempuan. Tanggerang: Lentera Hati. 2005.109.

Sugarda, Tarya. Pengantar Studi Sosiologi Kelurga. Bandung: CV

Syarifuddin, Amir. Hukum Perkawinan Islam di Indonesia antara Fiqih Munakahat dengan Undang-Undang Perkawinan. Jakarta: Kencana. 2007.

Tafsir ath-Thabari, 19/247 Baldatun Thayyibatun Wa Rabbun Ghafur.

Tanzeh, Ahmad. Metodologi Penelitian Praktis. Depok Sleman Yogyakarta: Penerbit Teras. 2011.89.

Todaro, Michael P. Pembangunan Ekonomi Di Dunia Ketiga. Jilid 1. Jakarta: Erlangga. 2000.

Utsman, Muhammad Ra'fat. Fikih Khitbah dan Nikah. Depok Jawa Barat Indonesia: 
PROFETIKA, Jurnal Studi Islam, Vol.21, No. 1, Special Issue 2020: 17-26

Fathan Media Prima. 2017.75.

Undang-Undang No.1 Tahun 1974 Tentang Perkawinan Pasal 7 ayat (1), ayat (2).

Wahab, Abdul. Fiqih Munakahat Khitbah, Nikah dan Talak. Jakarta: AMZAH. 2009.

WHO dan Depkes, Konsep Perkawinan. Jakarta: Depkes RI. 2010.

Zuraidah. "Analisis Pencapaian Pendewasaan Usia Perkawinan Di Kecamatan Pancurbatu Kabupaten Deli Serdang Tahun 2015". Jurnal Penelitian Kesehatan Suara Forikes. 2016; Vol. VII (1). 